Schiller, Dan. How to Think about Information. Urbana: University of Illinois Press, 2007. 267p. \$35 (ISBN 0252031326). LC 2006-011275.

It would be almost impossible to imagine any book title whose fulfillment could possibly be more different than just twenty years ago. The production, array, and consumption of information right now are enormously more complicated and confusing than they were then, and no one knows exactly in which directions these will go in the near and more distant future. Twenty years ago, "information" was more exiguous and certainly harder to come by, and often more effort was put into finding information than in digesting it. In contrast, today the problems begin with determining in which of numerous formats one wishes to have information brought to his or her attention. Even so, digesting is still an issue, and the question is: does this encourage more or less careful interpretation of it?

As befits a member of the School of Library and Information Science and the Institute of Communications Research at the University of Illinois, Dan Schiller operates at a rarefied level and does not really address the kinds of contexts with which librarians must grapple on a daily basis ("libraries" barely makes the index). Rather, he is concerned with, as he puts it, "information as a commodity." Indeed, Schiller expresses his focus almost at once: "[h]ow, when and why does information become economically valuable?" In these circumstances, it is surprising that he fails to discuss one information-as-commodity issue of supreme consequence to libraries - the increasingly high costs of information (would that it were also always knowledge!) to both libraries and individuals.

Instead, the present work is aimed at technocrats, macroeconomists, and others who are interested in developing abstracted notions of information. Working librarians, faced with an overwhelming tidal wave of both information and ways to gain access to it, will probably not find it possible to "think" about this information beyond trying their best to ensure that the most and the best of it reaches the user. And then, of course, the users themselves will need to learn how to domesticate this mass in whatever ways appear to suit their particular purposes best.

Nor does Schiller spend any time ruminating about another, admittedly only epistemological, concern-the effects of the information explosion on our ability to comprehend, in both senses, the results. One concept that will perish as a result of these new sets of circumstances is the very notion of "definitiveness." With information now changing kaleidoscopically, and being measured in terabytes (one terabyte equals 1,000,000,000,000 bytes), and with our individual and collective gray matter continuing blithely along imperceptible evolutionary paths, it will soon become impossible-if it isn't already - to capture the totality of even the thinnest slice of the universe of information. Like astronomers who, while developing newer and better instruments, recognize that they are falling behind the curve, librarians increasingly are finding themselves able to provide more in absolute terms but less in relative terms, and there seems no way out of this impasse.

In sum, while most libraries should have a copy of How to Think about Information, there seems to be no pressing reasons why librarians need to assimilate its arguments for themselves, given all the other concerns that coping with "information" now puts on the table-David Henige, University of Wisconsin-Madison.

\section{Stueart, Robert D. International Librarian- ship: A Basic Guide to Global Knowledge Access. Lanham, Md.: Scarecrow (Li- braries and Librarianship: An Interna- tional Perspective, No. 2), 2007. 247p. alk. paper, $\$ 45$ (ISBN 0810858762). LC 2006-22209.}

Robert D. Stueart's International Librarianship: A Basic Guide to Global Knowledge Access is the second in an ambitious series entitled Libraries and Librarianship: An 